University of Nebraska - Lincoln

DigitalCommons@University of Nebraska - Lincoln

Faculty Publications, Department of

Mathematics

Mathematics, Department of

$5-17-2019$

\title{
Predicting impacts of chemicals from organisms to ecosystem service delivery: A case study of insecticide impacts on a freshwater lake
}

\author{
Nika Galic \\ Syngenta Crop Protection LLC., nika.galic@syngenta.com \\ Chris J. Salice \\ Towson University \\ Bjorn Birnir \\ University of California- Santa Barbara \\ Randall J.F. Bruins \\ US Environmental Protection Agency \\ Virginie Ducrot \\ Crop Science Division
}

See next page for additional authors

Follow this and additional works at: https://digitalcommons.unl.edu/mathfacpub

Part of the Applied Mathematics Commons, and the Mathematics Commons

Galic, Nika; Salice, Chris J.; Birnir, Bjorn; Bruins, Randall J.F.; Ducrot, Virginie; Jager, Henriette I.; Kanarek, Andrew; Pastorok, Roberto; Rebarber, Richard; Thorbek, Pernille; and Forbes, Valery E., "Predicting impacts of chemicals from organisms to ecosystem service delivery: A case study of insecticide impacts on a freshwater lake" (2019). Faculty Publications, Department of Mathematics. 231.

https://digitalcommons.unl.edu/mathfacpub/231

This Article is brought to you for free and open access by the Mathematics, Department of at DigitalCommons@University of Nebraska - Lincoln. It has been accepted for inclusion in Faculty Publications, Department of Mathematics by an authorized administrator of DigitalCommons@University of Nebraska - Lincoln. 


\section{Authors}

Nika Galic, Chris J. Salice, Bjorn Birnir, Randall J.F. Bruins, Virginie Ducrot, Henriette I. Jager, Andrew Kanarek, Roberto Pastorok, Richard Rebarber, Pernille Thorbek, and Valery E. Forbes 


\title{
Predicting impacts of chemicals from organisms to ecosystem service delivery: A case study of insecticide impacts on a freshwater lake
}

\author{
Nika Galic ${ }^{\mathrm{a}, *}$, Chris J. Salice ${ }^{\mathrm{b}}$, Bjorn Birnir ${ }^{\mathrm{c}}$, Randall J.F. Bruins ${ }^{\mathrm{d}}$, Virginie Ducrot ${ }^{\mathrm{e}}$, Henriette I. Jager ${ }^{\mathrm{f}}$, \\ Andrew Kanarek ${ }^{\mathrm{g}}$, Robert Pastorok ${ }^{\mathrm{h}}$, Richard Rebarber ${ }^{\mathrm{i}}$, Pernille Thorbek ${ }^{\mathrm{j}, 1}$, Valery E. Forbes ${ }^{\mathrm{k}}$ \\ a Syngenta Crop Protection LLC., Greensboro, NC, USA \\ b Environmental Science and Studies Program, and the Department of Biological Sciences, Towson University, Towson, MD, USA \\ c Center for Complex and Nonlinear Science and Department of Mathematics, University of California Santa Barbara, Santa Barbara, CA, USA \\ d Systems Exposure Division, National Exposure Research Laboratory, US Environmental Protection Agency, Cincinnati, Ohio, USA; retired \\ e Bayer AG, Crop Science Division, Monheim am Rhein, Germany \\ ${ }^{\mathrm{f}}$ Environmental Sciences Division, Oak Ridge National Laboratory, Oak Ridge, TN, USA \\ ${ }^{g}$ National Institute for Mathematical and Biological Synthesis, University of Tennessee, Knoxville, TN, USA \\ ${ }^{\text {h }}$ Ecology Group, Integral Consulting, Woodinville, WA, USA \\ ${ }^{i}$ Department of Mathematics, University of Nebraska, Lincoln, NE, USA \\ j Environmental Safety, Syngenta, Jealott's Hill International Research Centre, Bracknell, United Kingdom \\ ${ }^{\mathrm{k}}$ Department of Ecology, Evolution and Behavior, University of Minnesota, St. Paul, MN, USA
}

\section{H I G H L I G H T S}

- Impacts of a hypothetical insecticide on ecosystem services provided by a lake were modeled.

- Complex response of fishing services due to non-linear feedbacks in the lake food web

- Water clarity increased with reduced insecticide use $\rightarrow$ increase in value by waders and swimmers.

- Models can generalize to meaningful endpoints and facilitate quantitative scenario comparison.

\section{G R A P H I C A L A B S T R A C T}

\begin{tabular}{|ll|}
\hline Toxicant $\longrightarrow$ SPU & FEevice Providing Units] $\quad$ [Final Ecosystem Goods and Services] \\
\hline
\end{tabular}

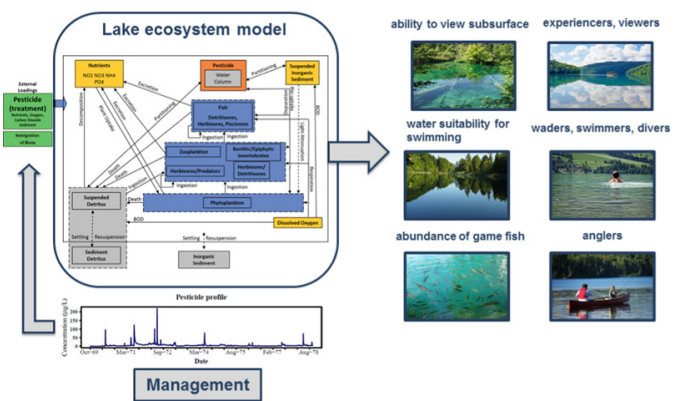

\section{A B S T R A C T}

Assessing and managing risks of anthropogenic activities to ecological systems is necessary to ensure sustained delivery of ecosystem services for future generations. Ecological models provide a means of quantitatively linking measured risk assessment endpoints with protection goals, by integrating potential chemical effects with species life history, ecological interactions, environmental drivers and other potential stressors. Here we demonstrate how an ecosystem modeling approach can be used to quantify insecticide-induced impacts on ecosystem services provided by a lake from toxicity data for organism-level endpoints. We used a publicly available aquatic ecosystem model AQUATOX that integrates environmental fate of chemicals and their impacts on food webs in aquatic environments. By simulating a range of exposure patterns, we illustrated how exposure to a hypothetical

\footnotetext{
* Corresponding author.

E-mail address: Nika.Galic@syngenta.com (N. Galic).

1 Current address: BASF SE, APD/EE, Limburgerhof, Germany.
} 
Keywords:

Ecosystem services

Aquatic ecosystem model

Ecological valuation

Fishers

Swimmers

Trophic cascade

Ecological risk assessment insecticide could affect aquatic species populations (e.g., recreational fish abundance) and environmental properties (e.g., water clarity) that would in turn affect delivery of ecosystem services. Different results were observed for different species of fish, thus the decision to manage the use of the insecticide for ecosystem services derived by anglers depends upon the favored species of fish. In our hypothetical shallow reservoir, water clarity was mostly driven by changes in food web dynamics, specifically the presence of zooplankton. In contrast to the complex response by fishing value, water clarity increased with reduced insecticide use, which produced a monotonic increase in value by waders and swimmers. Our study clearly showed the importance of considering nonlinear ecosystem feedbacks where the presence of insecticide changed the modeled food-web dynamics in unexpected ways. Our study highlights one of the main advantages of using ecological models for risk assessment, namely the ability to generalize to meaningful levels of organization and to facilitate quantitative comparisons among alternative scenarios and associated trade-offs among them while explicitly accounting for different groups of beneficiaries.

(c) 2019 Elsevier B.V. All rights reserved.

\section{Introduction}

Ecosystems provide various goods and services to human beneficiaries. These include food and water, flood protection, climate regulation, and recreational opportunities (Fisher et al., 2009). Processes at the population, community, and ecosystem scale contribute to various degrees to the delivery of ecosystem services (Luck et al., 2003). At the same time, anthropogenic activities can potentially affect different ecosystems and components adversely, thus interrupting service delivery (Johnston et al., 2015; Tilman et al., 2017). Assessing and managing risks of anthropogenic activities to ecological systems is necessary to ensure sustained delivery of ecosystem services for future generations.

Ecological risk assessment quantifies potential impacts on different receptors (e.g. species), and typically focuses on individual responses of a small set of representative species (Hommen et al., 2010). However, when assessing potential environmental risks from chemicals, we are interested in how chemicals might affect higher levels of organization, such as populations (Efroymson et al., 2004), habitats (Efroymson et al., 2010), ecological communities (Suter et al., 1999), ecosystems and the services that they provide (Nienstedt et al., 2012).

When considering ecosystem services, relevant assessment endpoints may be at the population or community level. Standard toxicity testing, the basis for chemical risk assessments, relies on testing a handful of species and focuses on effects at the individual level (Forbes and Galic, 2016). For example, in freshwater ecosystems phytoplankton, invertebrates and fish are often used as test organisms (Hommen et al., 2010). Even though impacts on their survival, growth, and reproduction are rigorously quantified and are assumed to be protective, these organisms and corresponding endpoints do not directly represent services that are valued by beneficiaries. Rather, beneficiaries may care about clean drinking water, clean water for recreation (swimming and boating), harvestable fish populations, and simply the aesthetic enjoyment of experiencing freshwater ecosystems (Dodds et al., 2008; Postel and Carpenter, 1997; Viscusi et al., 2008).

Ecological models provide a means of quantitatively linking measured risk assessment endpoints with protection goals (Forbes and Galic, 2016; Forbes et al., 2017). By integrating potential chemical effects with species life history, ecological interactions, environmental drivers and other potential stressors, we can predict long-term risks to ecological entities that deliver valued ecosystem services (De Laender and Janssen, 2013; Galic et al., 2012). Furthermore, we can easily and inexpensively evaluate multiple management options and quantify tradeoffs among multiple services (Bennett et al., 2009).

The aim of this study was to demonstrate how an ecosystem modeling approach can be used to quantify insecticide-induced impacts on ecosystem services from organism-level toxicity data. The case study was developed as one of the outputs of a National Institute of Mathematical and Biological Synthesis (NIMBioS) working group hosted by the University of Tennessee in Knoxville (http://www.nimbios.org/ workinggroups/WG_02e). It represents an example of a recently- developed framework for extrapolating impacts of chemicals from individual organisms to ecosystem services (Forbes et al., 2017).

The approach taken here was to quantify the benefits derived from a Midwestern US lake relative to potential effects of a hypothetical insecticide across a range of exposure scenarios, based on possible mitigation measures. We purposefully applied exposure scenarios that ensured a large disruption to the lake ecosystem to observe and quantify impacts on ecosystem services and any associated trade-offs. A well-tested lake ecosystem model was used to simulate the effects of a hypothetical insecticide on sensitive aquatic crustaceans and fish species. The main beneficiaries of ecosystem services were identified and provided by a generic lake in the Midwestern US as recreational fishers, swimmers and boaters. We focused on final ecosystem goods and services (FEGS), i.e., those directly used or enjoyed by beneficiaries (Boyd and Banzhaf, 2007; Bruins et al., 2017). A distinction is made between final (direct) and intermediate (indirect) ecosystem services. For example, most supporting services such as primary production or nutrient cycling are intermediate because, although they are not directly valued by the public, they support populations of game fish that are directly valued.

By simulating a range of exposure patterns, we illustrated how risks from exposure to this hypothetical insecticide could affect aquatic species populations (e.g., recreational fish abundance) and environmental properties (e.g., water clarity) that would in turn affect delivery of ecosystem services. We used a publicly available aquatic ecosystem model AQUATOX (Park et al., 2008), supported by the US Environmental Protection Agency. This model integrates environmental fate of chemicals and their impacts on generic and specific food webs in aquatic environments. It may be used for assessing impacts on aquatic ecosystems (Clough et al., 2017; Park et al., 2008), and a number of site- and condition-specific scenarios exist that are readily available to use.

Impacts were translated on ecological entities to changes in services delivered to beneficiaries, and benefits transfer methods were used to assign economic values to them (Richardson et al., 2015). We further assumed that certain mitigation measures (e.g., changes in insecticide application rate or frequency or presence of buffers) would change the insecticide loading that reaches the lake food web. We compared several management options to demonstrate how applying a biophysical model can advance our capabilities beyond risk assessment, i.e., to inform decision-making to improve the management of ecosystems facing various pressures from anthropogenic activities.

\section{Methods}

\subsection{AQUATOX model}

AQUATOX is an aquatic ecosystem simulation model, which was developed by the US Environmental Protection Agency, that links the physical or abiotic environment (i.e., water quality) and aquatic communities (Park et al., 2008). In this process-based mechanistic model, different communities are represented as compartments of biomass 
that change based on the gains and losses defined for each group. In a series of linked differential equations, biomass is gained through growth, reproduction and external inflow, whereas biomass is lost through natural mortality, respiration, predation, exposure to toxicants, and emigration. The model also simulates cycling of all major nutrients, oxygen dynamics, and different fate processes for organic toxicants (Fig. 1). By simultaneously computing important chemical and biological processes over time, the model helps to identify cause-effect relationships between chemical water quality, the physical environment, and aquatic communities.

AQUATOX version 3.1 has been applied to simulate multiple environmental stressors (including nutrients, organic loadings, sediments, chemicals, and temperature) and their effects on algal, macrophyte, invertebrate, and fish communities. Various model applications have represented different aquatic ecosystems, including vertically stratified lakes, reservoirs and ponds, rivers and streams, and estuaries (Clough et al., 2017).

Appendix B of Park and Clough (2014) includes the full list of pointestimate parameters describing biota, chemicals, sites, and remineralization, their units, and their manner of reference in the AQUATOX software interface. The AQUATOX model is written in object-oriented Pascal using the Delphi programming system for Windows. As part of a case study scenario, initial conditions are set for state variables. Site characteristics and any parameter estimates that differ from AQUATOX default values are specified as part of each scenario. Details on the equations in AQUATOX, its developmental history, and use are provided in the technical documentation (Park and Clough, 2014).

\subsection{Case study description}

We chose to model the aquatic ecosystem of a generic reservoir in the Midwestern US for this case study because such lake systems are popular recreation destinations and therefore offer an opportunity to evaluate potential tradeoffs among ecosystem services (Fig. 2). As a starting point, we focused on a well-studied system, but modified it to represent a clear reservoir that would increase its attractiveness to the public. We identified Coralville Reservoir (CR), which we used as a template to build a simulation model for a generic shallow reservoir in Johnston County, Iowa (USA). It is also one of the study files that is included in the installation of the AQUATOX software. Coralville Reservoir is a run-of-river reservoir that is influenced by agricultural runoff (Schnoor, 1981). As a result, the reservoir often experiences high turbidity that substantially limits phytoplankton growth. Simulations of toxicant impacts on zooplankton with original CR parameters did not cause substantial changes in biomass of phytoplankton or in turbidity because the influence of inorganic solids (i.e., silt from agricultural lands) was so dominant. Therefore, we restricted that influence to represent a reservoir/lake without substantial riverine inputs of suspended inorganic solids.

The approach to parameterization included an iterative process of adjusting a few parameters for site characteristics and biota to achieve a model reservoir in which phytoplankton dominate over submerged aquatic macrophytes, and an impact on herbivorous zooplankton leads to higher biomass of phytoplankton. The food web used in our lake model included four species of forage fish (bluegill, shad, catfish, and buffalofish), two piscivorous fish species (walleye and largemouth bass), four zooplankton functional taxa (daphnids, rotifers, copepods, and predatory zooplankton, i.e. Chaoborus), three benthic/epiphytic functional taxa (chironomids, Tubifex, and sphaerids), and four phytoplankton taxa (diatoms, dinoflagellates, and green and blue-green algae) (Forbes et al., 2017 - Fig. 3; Fig. 1). This is a realistic food-web dynamic in small lakes and reservoirs (Carpenter et al., 2010; Carpenter et al., 1985) and provides an opportunity to examine tradeoffs among ecosystem services. A more detailed description of these modifications, as well as the information on initial conditions, can be found in the Supplementary Information (Table SI 1 and SI 3). Due to our modifications, in the following we refer to this model system as the "case study reservoir".

For this case study, we assumed that the reservoir is exposed to a hypothetical organophosphate insecticide. For simulation purposes, we used available toxicity data for a representative organophosphate

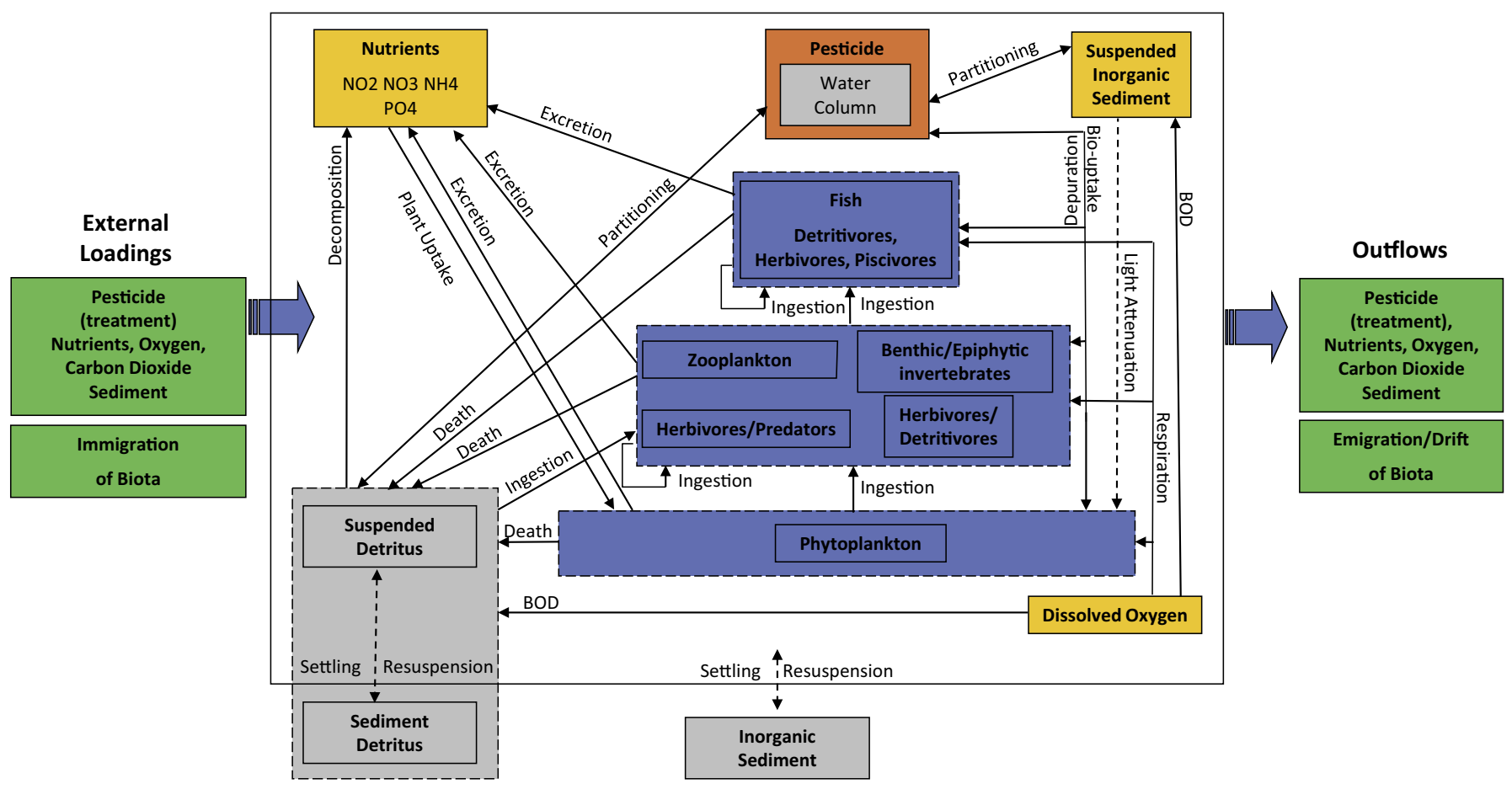

Fig. 1. Conceptual representation of different compartments represented in AQUATOX. 
FEGS

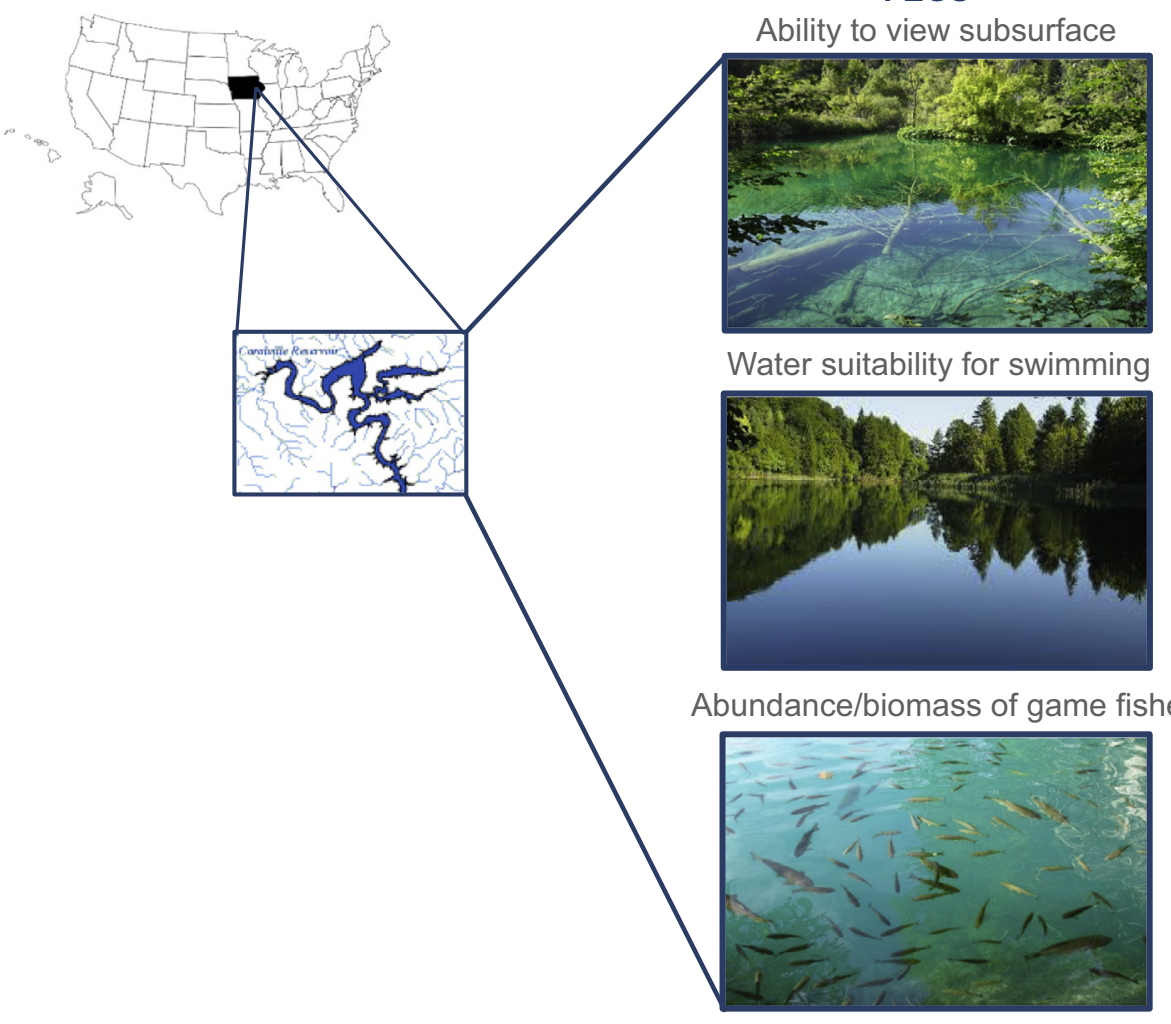

Beneficiaries

Experiencers, Viewers

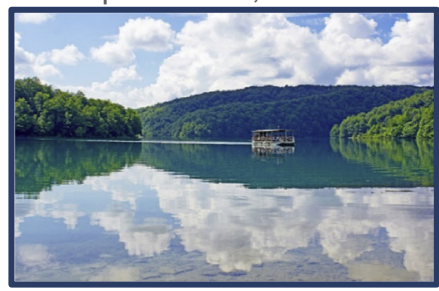

Waders, Swimmers, and Divers

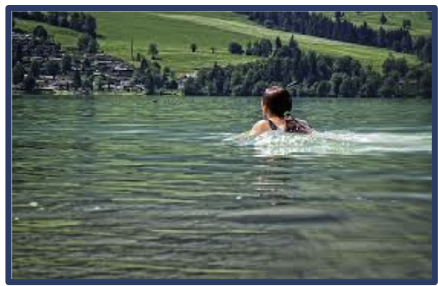

Anglers

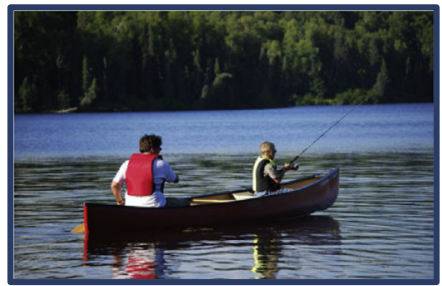

Fig. 2. Final ecosystem goods and services (FEGS) provided by a reservoir lake, representative of Midwestern lakes, and their beneficiaries.

insecticide that is registered for use on corn, which is the predominant crop in the watershed of the Coralville Reservoir. The case study chemical was slightly mobile in soil $\left(\mathrm{K}_{\mathrm{oc}}=6040 \mathrm{~L} / \mathrm{kg}\right.$ organic $\left.\mathrm{C}\right)$ and moderately persistent (aerobic soil metabolism $t_{1 / 2}=170 \mathrm{~d}$ ). The most sensitive taxa to this insecticide include zooplankton, especially cladocerans (i.e. Daphnia sp.), and pan fish, such as bluegill, followed by walleye and largemouth bass. Catfish and buffalo fish were the least sensitive. AQUATOX implements acute (mortality) and chronic (growth and reproduction) toxicity data in concentration-effects functions to simulate chemical impacts on biomass of different taxa (Park and Clough, 2014). We used surrogate species for those for which toxicity data were lacking; a table with all toxicity parameters used in this case study can be found in the Supplementary Information (Table SI 2 ). We made the conservative assumption that all agricultural land in the watershed was used for growing corn, i.e., $57 \%$ of the total watershed area (www.nrcs.usda.gov/Internet/FSE_DOCUMENTS/nrcs142p2_ 006352.pdf). Water concentrations of the case study insecticide loading were modeled using the Pesticide Root Zone Model (PRZM, version 5.0) (https://www.epa.gov/exposure-assessment-models/przm-versionindex) and the Variable Volume Water Model (VVWM), assuming labelrate insecticide application to all corn acreage (applied at $1.68 \mathrm{~kg}$ active ingredient/ha, twice per year) in the Coralville Reservoir watershed. PRZM is a simulation model that takes into account rainfall and evapotranspiration, as well as agricultural practices, to calculate daily fate of the pesticide in the field. Each PRZM scenario can be a unique combination of climatic conditions, crop-specific management practices, soilspecific properties, site-specific hydrology, and pesticide-specific application and dissipation processes (Young and Fry, 2016). Simulation outputs are daily edge-of-field runoff and spray drift loadings of pesticide which are discharged into a standard water body simulated by the VVWM (Young, 2016). This model simulates daily pesticide concentrations accounting for the processes of volatilization, sorption, hydrolysis, biodegradation, and photolysis.
Historical simulations were conducted for the period between October 1969 and September 1978 - the choice of the simulation period was driven by the availability of weather profiles in the original AQUATOX template. The same weather profiles were used to generate insecticide concentrations in PRZM and VVWM. We further simulated several management scenarios (MS) by reducing insecticide loading by different amounts. This was done assuming a reduced pesticide load (i.e. $10 \times, 25 \times$ or $100 \times$ ), but the same temporal exposure pattern. We simulated the following management scenarios: no reduction (MS 0 ), a $5 \times$ reduction (MS 5), a $10 \times$ reduction (MS 10), a $25 \times$ reduction (MS 25), a 100× reduction (MS 100 ), and a complete absence of the insecticide (MS No pesticide). Management scenarios represent a reduction in total loading of the insecticide into the watershed through a combination of relevant mitigation measures. Conceptually, a given management scenario may be achieved through a combination of actions, including reduced application rates, fewer applications per field (not tested in this study) or use of riparian buffers; however, this analysis does not quantify impacts of specific actions on loading.

\subsection{Selection and valuation of ecosystem services}

For this case study, ecosystem services were identified using U.S. EPA's Final Ecosystem Goods and Services Classification System, or FEGS-CS (Landers and Nahlik, 2013). The FEGS-CS classifies environments and the corresponding ecological components that are directly enjoyed by different classes of beneficiaries.

Ecosystem services relevant to Midwestern reservoirs included the ability to view the lake bottom in wading areas, abundance of game fish, and water suitability for swimming (Table 1 ). We then identified corresponding metrics that could be estimated using AQUATOX outputs (Table 1). Finally, we selected abundance of game fish and water suitability for recreational purposes for economic valuation which was 
Table 1

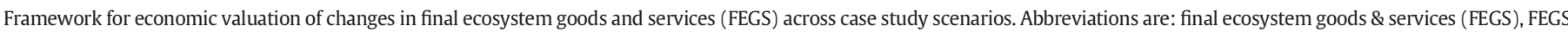
classification system (FEGS-CS), and willingness-to-pay (WTP).

\begin{tabular}{|c|c|c|c|c|c|}
\hline \multicolumn{2}{|l|}{ FEGS } & \multicolumn{2}{|l|}{ Beneficiary } & \multirow[t]{2}{*}{ Available benefit transfer data } & \multirow{2}{*}{$\begin{array}{l}\text { Corresponding model } \\
\text { endpoint }\end{array}$} \\
\hline From FEGS-CS & $\begin{array}{l}\text { In case } \\
\text { study }\end{array}$ & From FEGS-CS & In case study & & \\
\hline $\begin{array}{l}\text { Presence of the } \\
\text { environment/water } \\
\text { suitability for swimming }\end{array}$ & $\begin{array}{l}\text { Mean } \\
\text { seasonal } \\
\text { Secchi depth } \\
(\mathrm{m})^{\mathrm{a}}\end{array}$ & $\begin{array}{l}\text { Recreational/waders, } \\
\text { swimmers, and divers }\end{array}$ & $\begin{array}{l}\text { Recreational users of the } \\
\text { case study reservoir }\end{array}$ & $\begin{array}{l}\text { WTP (Iowans' travel to Iowa } \\
\text { lakes) for change in water clarity } \\
=\$ 0.21 \mathrm{~m}^{-1} \text { household }{ }^{-1} \text { lake }^{-1} \\
\mathrm{y}^{-1} \\
\text { (Egan et al., 2009) }\end{array}$ & $\begin{array}{l}\text { Change in seasonal Secchi depth } \\
(\mathrm{m}) \text { in different management } \\
\text { scenarios }\end{array}$ \\
\hline $\begin{array}{l}\text { Presence of the } \\
\text { environment/ability to } \\
\text { view subsurface } \\
\text { environment }\end{array}$ & $\begin{array}{l}\text { Mean } \\
\text { seasonal } \\
\text { Secchi depth } \\
(\mathrm{m})^{\mathrm{a}}\end{array}$ & $\begin{array}{l}\text { Recreational/experiencers } \\
\text { and viewers }\end{array}$ & $\begin{array}{l}\text { General public and } \\
\text { property owners at the } \\
\text { case study reservoir }\end{array}$ & $\begin{array}{l}\text { This FEGS was assumed to overlap } \\
\text { with the previous one }\end{array}$ & Change in Secchi depth (m) \\
\hline $\begin{array}{l}\text { Fish/abundances of game } \\
\text { fish }\end{array}$ & $\begin{array}{l}\text { Biomass of } \\
\text { several fish } \\
\text { species }\end{array}$ & Recreational/anglers & $\begin{array}{l}\text { Recreational anglers of } \\
\text { the case study reservoir }\end{array}$ & $\begin{array}{l}\text { WTP (Michigan anglers' travel to } \\
\text { Michigan rivers, streams, } \\
\text { impoundments) per additional } \\
\text { fish caught }=\$ 1.55 \text { for panfish, } \\
\$ 1.57 \text { for largemouth bass, } \$ 4.03 \\
\text { for walleye (Melstrom et al., } \\
2015 \text { ) }\end{array}$ & $\begin{array}{l}\text { Change in biomass of the four } \\
\text { species of interest for angling: } \\
\text { largemouth bass, walleye, bluegill, } \\
\text { catfish }\end{array}$ \\
\hline
\end{tabular}

\footnotetext{
a Secchi depths are defined as the number of meters beneath the surface of the water where a Secchi disk is visible.
}

conducted using the benefits transfer method (Richardson et al., 2015). This required us to assume that the transferred values pertain to this case study and that the demographics of beneficiaries are similar. Below we describe valuation methods for abundance of game fish and the suitability of a water body for wading or swimming.

\subsubsection{Abundance of game fish}

To illustrate valuation of this ecosystem service, the potential for fishing in the reservoir was translated from fish biomass $(\rho)$ generated by AQUATOX to value $(V)$ in dollars of a specific MS $(i)$ of the insecticide loading (i.e., $25 \times$ decrease, $10 \times$ decrease, no insecticide use in the watershed). The focus of this analysis was on an annual change in the value of fishing that could be attributed to a specific type of fish (i.e., bluegill, bass, walleye or catfish). An annual time step $(t)$ seemed most realistic for the time frame in which watershed and reservoir managers could collect data (e.g., crop practices, number of anglers visiting the reservoir, etc.) and make decisions.

For each type of fish, daily biomass values were generated by AQUATOX (dry weight) for the baseline scenario (i.e., insecticide use as on label) and for the three management scenarios. These values were then converted from a dry to a wet weight (U.S. Environmental Protection Agency, 1993). The daily change in biomass attributed to a management scenario was calculated as the difference between the biomass in the management and baseline scenarios. For each of the simulated full years (1970-1977), an average daily change in biomass $\rho$ was calculated (Eq. (1)) for each year $t$ and type of fish $i$ :

$\Delta \bar{\rho}_{i}=\frac{1}{365} \sum_{t=1}^{365}\left(\rho_{i, t}-\rho_{\text {base }, t}\right)$

For each year and each type of fish, the value of an insecticide management scenario ( $\$ ; V_{i}$; Eq. (2)) was calculated by multiplying the daily change in density by willingness of fishers to pay (WTP) for a change in fish biomass and the number of visits to the lake per year $(N)$

$V_{i}=\Delta \bar{\rho} \times W T P \times N$

There were 187,382 visits to the reservoir in 2012 for fishing (U.S. Army Corps of Engineers, 2014), and we used 187, 000 as the value for all simulation years in further analyses. WTP data used in this analysis were expressed as average cost (\$) per trip per $\mathrm{kg} / \mathrm{ha}$ increase in a given type of fish. We assumed that all trips were attributed to a single species and that there were no species preferences, i.e., trips were not taken to fish for a specific species. This allowed us to weigh all species equally for comparison. We used the following WTP: $\$ 1.55$ for bluegill (type of panfish), $\$ 1.57$ for largemouth bass and $\$ 4.03$ for walleye (Melstrom et al., 2015). Comparable WTP data for the Midwest were not found for catfish; however, some sources suggest that catfish may be valued at a similar level as panfish and bass and half of the value of walleye (Charbonneau and Hay, 1978). We, therefore, used the cost per trip value of $\$ 1.55$, which corresponds to bluegill, as a surrogate for catfish.

\subsubsection{Water suitability for wading or swimming}

The goal of this analysis was to illustrate a valuation of improved water clarity in the simulated reservoir. Water clarity is an important ecosystem service that is valued by different types of beneficiary (Fig. 2), including swimmers, boaters, and property owners; it has been identified as the best measure of high-quality water (Kosten et al., 2009; Peeters et al., 2009). Surveys show that clear water, measured by how many meters beneath the surface of the water a Secchi disk is visible, is highly valued by the general public (Schuetz et al., 2001). This is because the public has an intuitive understanding of what it means, and that it is a single aggregated measure reflecting a range of watershed impairments leading to eutrophication or high suspended sediment concentrations. A positive hyperbolic relationship exists between water clarity and an index of water quality (based on several parameters, incl. dissolved oxygen, $\mathrm{pH}$, total phosphorus, nitrates, turbidity) (Ge et al., 2013). There is a threshold increase at relatively low Secchi depths $(<1 \mathrm{~m})$, which means that small increases in Secchi depths will yield large increases in perceived water quality. Secchi depths were generated in AQUATOX simulations for the scenarios described in the Case Study Description (Section 2.2). Our valuation considered the impact of management scenarios on the hypothetical insecticide. We examined the literature to determine what expressions of Secchi depth (SD) should be used to evaluate FEGS for recreational users of the modeled lake.

We relied on a water clarity valuation model developed using 2002 water quality data and a survey of Iowa households to quantify recreational visits to Iowa lakes in the same year (Egan et al., 2009). The resulting logistic model linked two responses: 1 ) the change in number of visits to lakes and 2) willingness-to-pay (WTP, 2009\$US/household) for increasing water clarity associated with a set of unimpaired lakes (annual median Secchi depth $=1.27 \mathrm{~m}$ ) compared to impaired lakes (annual median Secchi depth $=0.81 \mathrm{~m}$ ). From this, we estimated a marginal value (per-meter increase in Secchi depth). We then summarized our simulated data for April-October, which is assumed to be the time period representative of the recreational season for swimmers and 
boaters. From that, we calculated median Secchi depths for each simulated year and scenario. From changes in clarity (differences in median Secchi depth between impaired and non-impaired lakes) we estimated changes in the number of trips and value per household. Water clarity is appreciated regionally, so the above estimates of value per household were expanded by estimating the number of households likely to visit the reservoir. The 2009 US Census estimated 55,967 households for Johnston County (where Coralville Reservoir is located), representing $4.2 \%$ of Iowa households (www.census.gov/2010census/popmap/ ipmtext.php?fl=19). The WTP data based on annual Secchi depth values were the only data available to us, and using these data for the valuation of our seasonal patterns is a clear limitation of this analysis. Ideally, we would prefer to use a value representative of the recreational period (e.g., median values representing Secchi depths from AprilOctober)

\section{Results}

\subsection{Ecosystem dynamics under exposure to a hypothetical insecticide}

Exposure to insecticide concentrations resulting from loadings provided by PRZM had substantial impacts on several taxa in the food web/ecosystem (relative to a scenario with no pesticide; Fig. 3). We show only a subset of compartments that AQUATOX simulated. Under the no management scenario (MS 0), biomass of daphnids, bluegill sunfish, and largemouth bass were kept low. Conversely, biomasses of phytoplankton and catfish benefitted from insecticide exposure and both increased. By applying different management scenarios that reduced exposure concentrations, we found concentration-response relationships that differed among taxa. For the majority of taxa, a $25 \times$ reduction in insecticide exposure (MS 25) yielded biomass values that did not visibly differ from those in which no insecticide was assumed (MS No pesticide). Bluegill biomass was reduced even at $100 \times$ reduction in exposure (MS 100, as compared with MS No pesticide), whereas catfish biomass declined as insecticide exposure decreased. In further analyses, we show only scenarios with no management (MS 0), with $10 \times$ reduction (MS 10), with $25 \times$ reduction (MS 25) and the scenario with no insecticide (MS No pesticide).

Catfish, bluegill sunfish, and largemouth bass experienced very different dynamics due to exposure in the four management scenarios (Fig. 4). We compared biomass in different scenarios to the scenario without any exposure (MS No pesticide). Bluegill biomass declined almost instantly after exposure to the insecticide and did not recover in the three management scenarios with partial reduction of insecticide loading. Biomass of largemouth bass was almost zero in the no management scenario and dropped substantially in MS 10 after 3 years of exposure, with a subsequent recovery after 3 additional years. Biomass dynamics of both largemouth bass and walleye were similar and consistently higher through the simulation period in MS 25 than in MS No pesticide (Fig. 4). Biomass of catfish consistently declined with reductions in exposure (MS $0>$ MS $10>$ MS $25>$ MS No pesticide).

Secchi depths varied across years and management scenarios (Fig. 5). The lower variability in 1969 was due to the simulation period capturing only the last 31 days of the season when the exposure concentrations were low, i.e. treatments were almost identical to controls for any management scenario. The exposure was high enough to
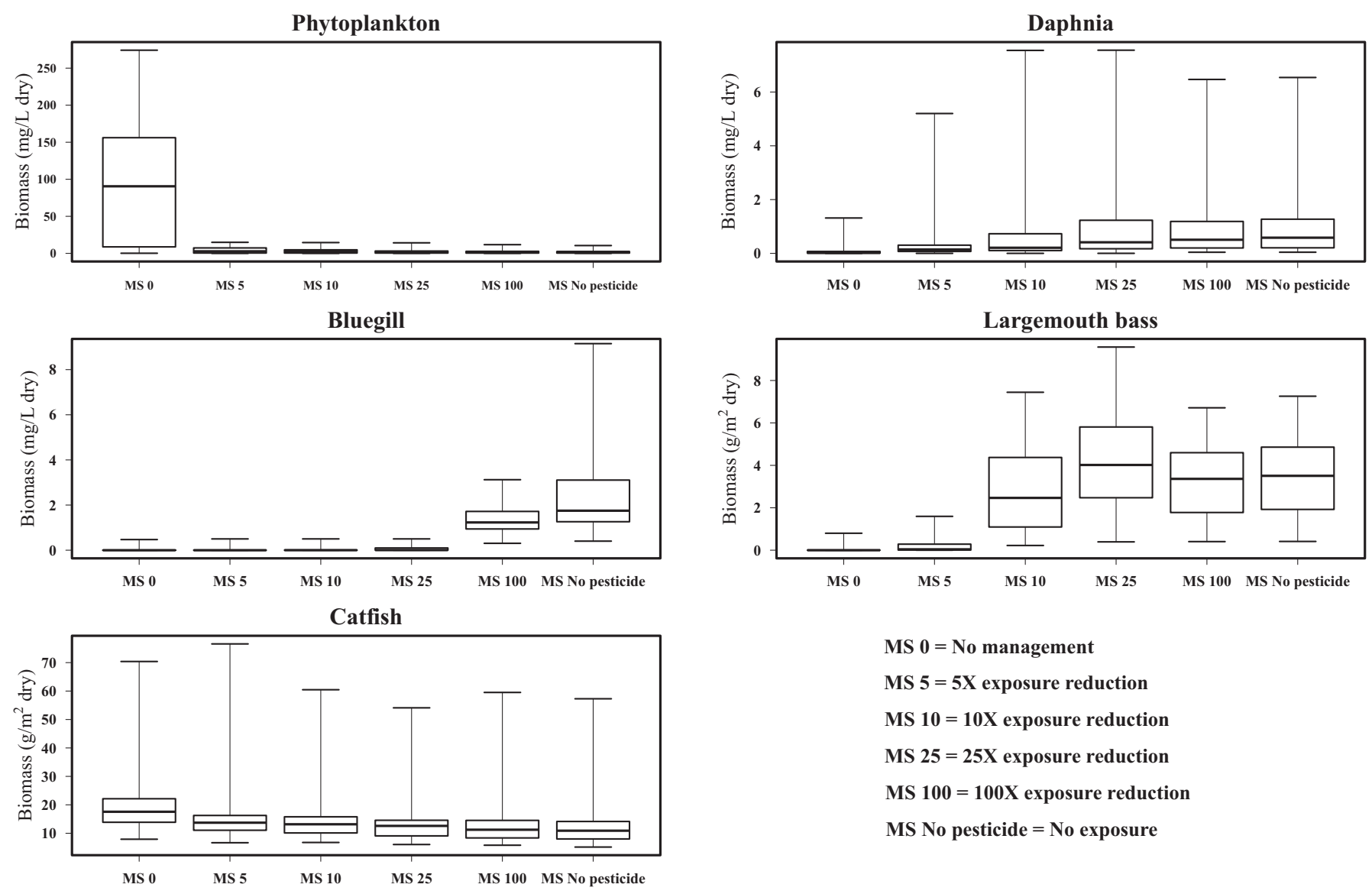

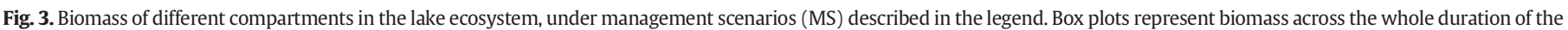
simulations. The boxes enclose the 25th and 75th percentile, the horizontal center line denotes median values, and boxplot whiskers extend to the minimum and maximum values. 
Bluegill

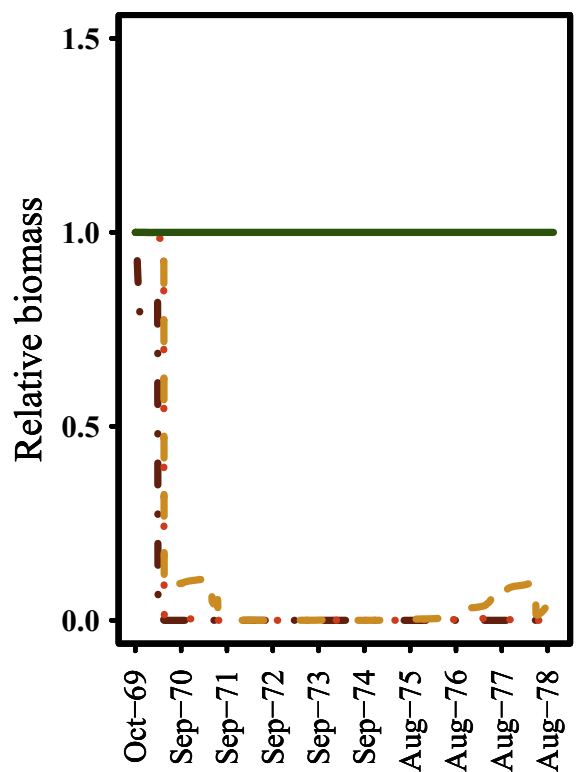

Largemouth bass

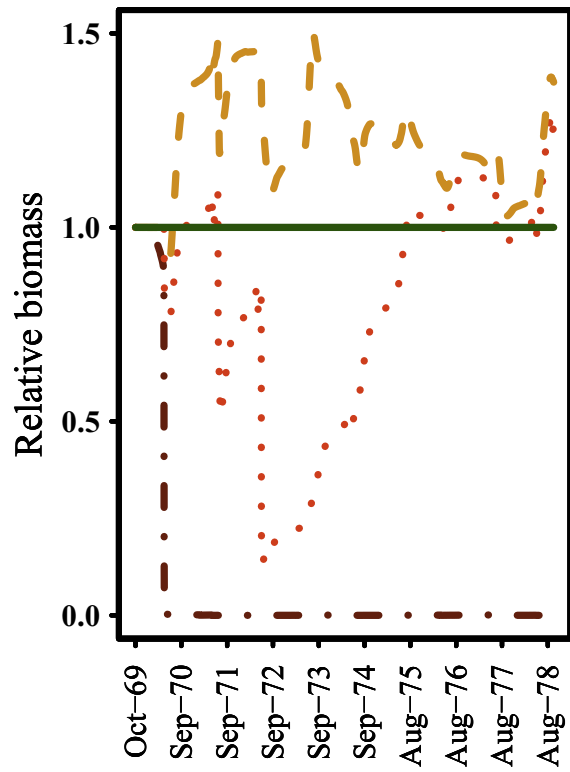

\section{Catfish}

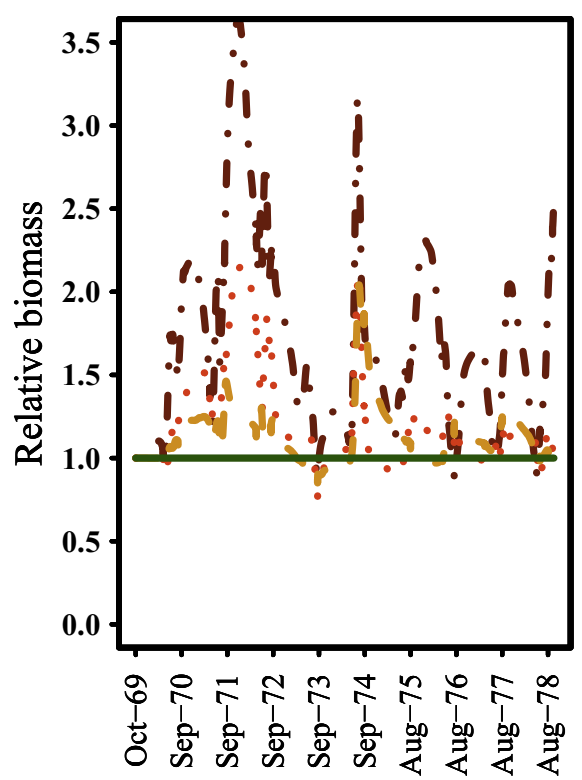

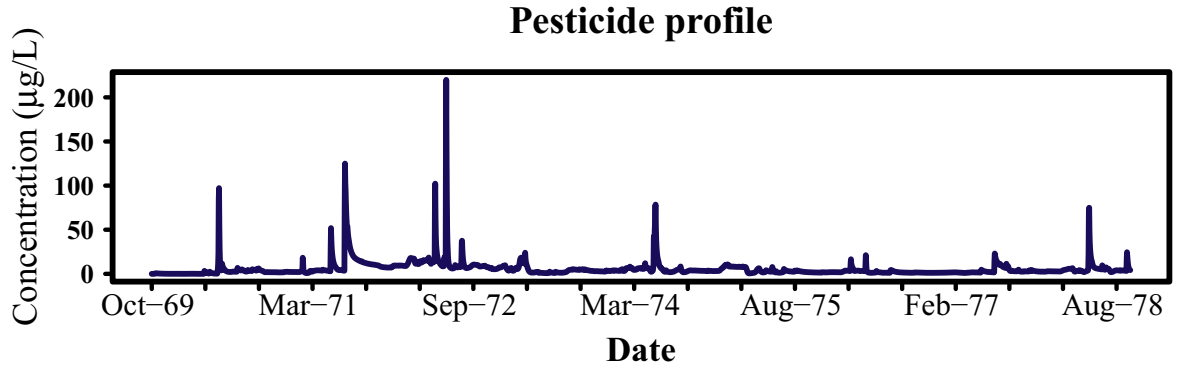

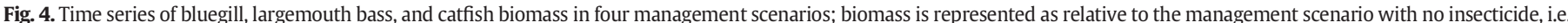

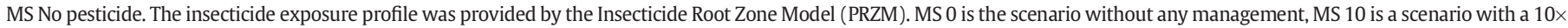
reduction in exposure, MS 25 is a scenario with a $25 \times$ reduction in exposure and MS No pesticide represents a scenario in which the insecticide was not used.

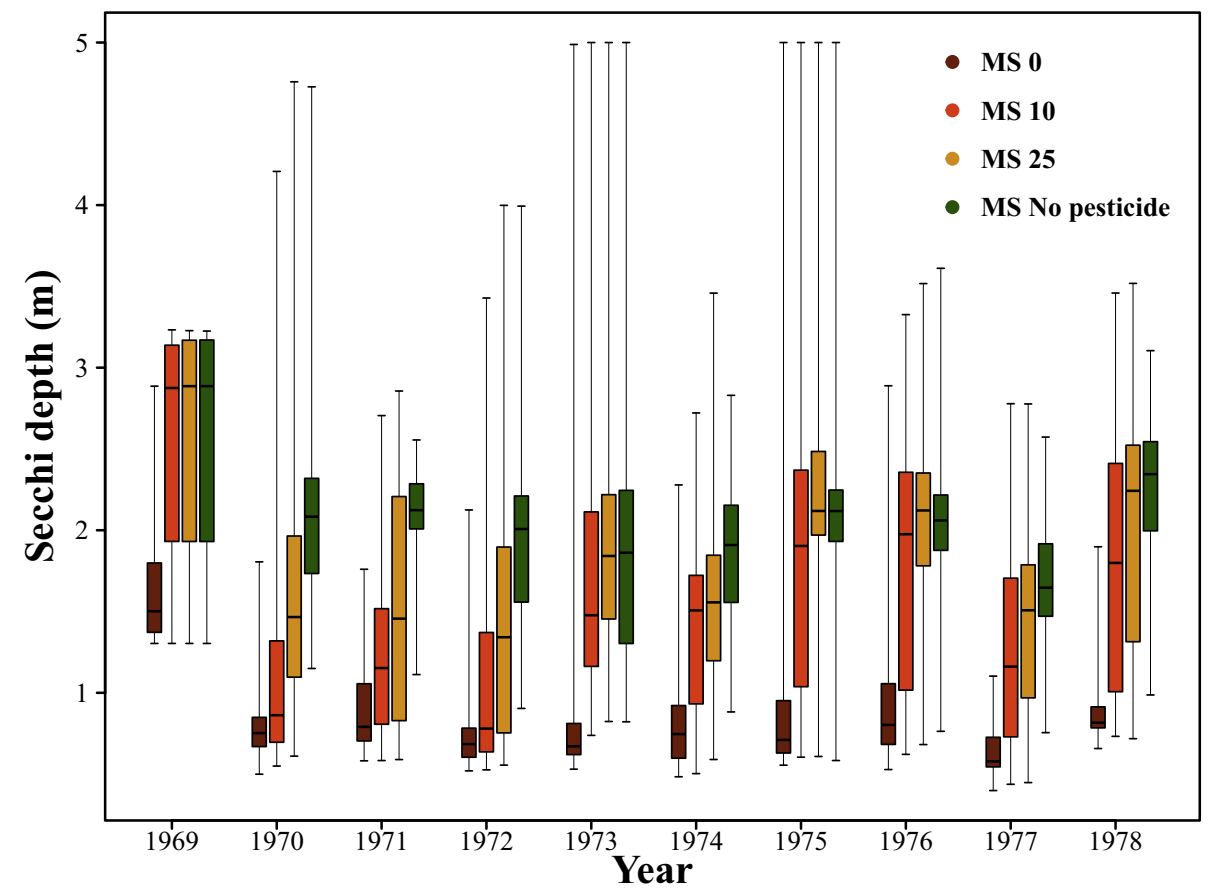

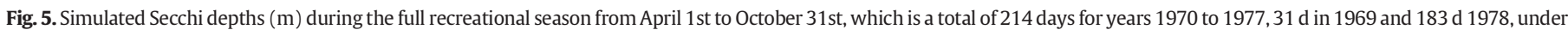

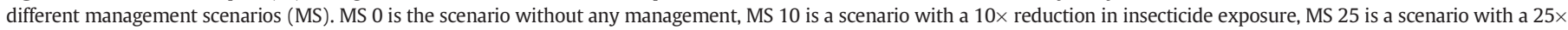

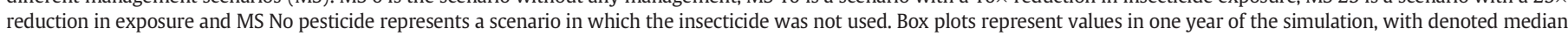
values, whereas box plot whiskers extend to the full range of values. 
perturb the system in the following season (spring 1970) which resulted in more variability across management scenarios and years. Nevertheless, there was a clear impact of the insecticide. In the years 1971-1972, when simulated concentrations were higher than in other years (Fig. 4), Secchi depths for all insecticide-use scenarios were smaller than in other years. Across all simulation years, mean water clarity in the recreational season was $0.88 \mathrm{~m}( \pm 0.51 \mathrm{SD})$ in the no management scenario, $1.5( \pm 0.8 \mathrm{SD})$ in the MS $10,1.8 \mathrm{~m}( \pm 0.77 \mathrm{SD})$ in the MS 25, and $2.02 \mathrm{~m}( \pm 0.6 \mathrm{SD})$ in the scenario with no insecticide use.

\subsection{Ecosystem services valuation}

\subsubsection{Abundance of game fish}

Valuation of the ecosystem service of abundance of game fish for anglers estimated the marginal values of management scenarios considered here over the baseline (MS 0) to increase between $\$ 300,000$ and $\$ 500,000$ for bass and walleye (Fig. 6), with overlapping confidence intervals. As walleye had the same responses as largemouth bass, values for both species were increased in the MS 25 when compared to MS No pesticide. Bluegill did not increase in value, except in the MS No pesticide scenario, in which the value was increased by $\$ 276,000$. Catfish decreased in value for all scenarios presented here. Decreases ranged from $\$ 500,000$ to $\$ 800,000$ over the nine year simulation period.

\subsubsection{Water suitability for swimming}

We estimated a marginal change in water clarity value of $\$ 0.21 \mathrm{~m}^{-1}$ household ${ }^{-1}$ lake $^{-1} \mathrm{y}^{-1}$ based on (Egan et al., 2009). The number of reservoir visits per household increased from a median below 0.1 for MS 10 to a median of 0.18 as exposure to the insecticide decreased (Fig. 7). This increase in visits was associated with a higher willingness to pay on a per-household basis for increased water clarity (results not shown). When expanded to the number of households in Johnston County, we estimated a regional economic benefit realized by waders and swimmers of between $\$ 6000$ (MS 10) and $\$ 15,000$ (MS No pesticide) (Fig. 7). Furthermore, the variability in values declined as the level of insecticide decreased in the simulated lake.

\section{Discussion}

The goal of this study was to use an ecological model to quantify changes in the provisioning of ecosystem services associated with

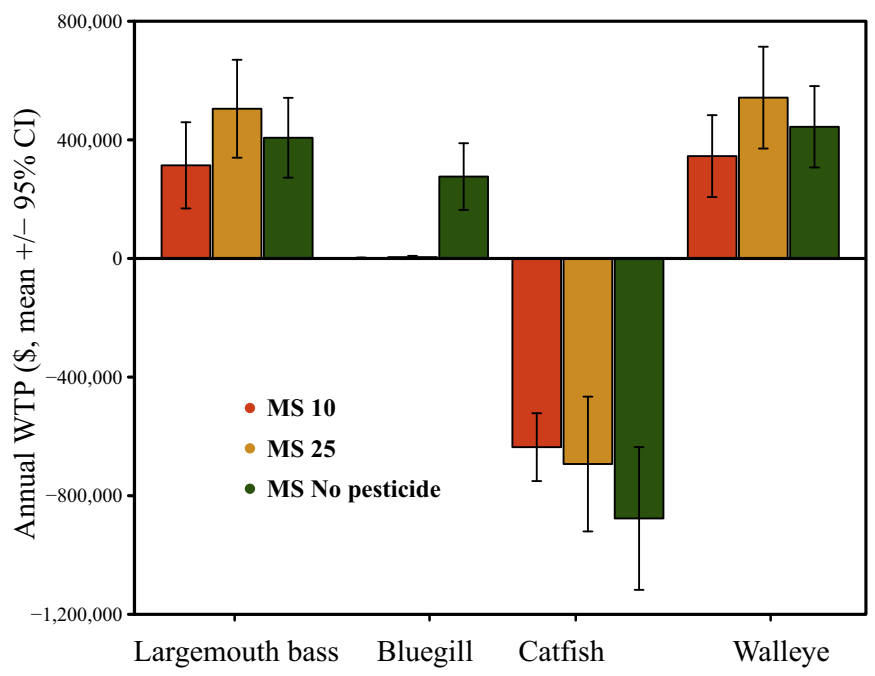

Fig. 6. Change in value associated with the ecosystem service of recreational fishing, estimated by willingness to pay (WTP), on four species in different management scenarios. Error bars represent 95\% confidence intervals around annual means. MS 10 is a scenario with a $10 \times$ reduction in exposure, MS 25 is a scenario with a $25 \times$ reduction in exposure and MS No pesticide represents a scenario in which the insecticide was not used. WTP is the willingness-to-pay for recreational fishing.

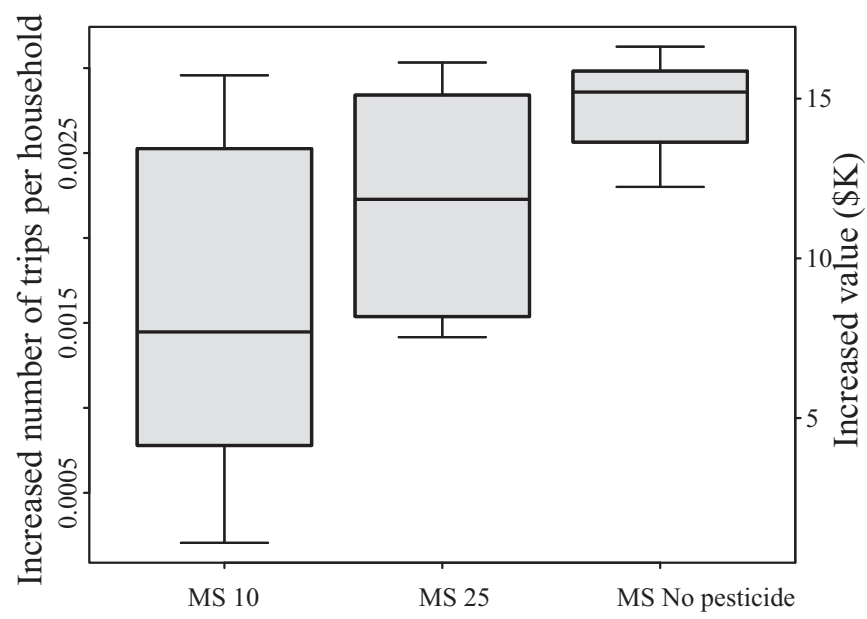

Fig. 7. Increased recreational use (left axis) and total value (right axis) across the county for Iowa swimmers. MS 10 is a scenario with a $10 \times$ reduction in insecticide exposure, MS 25 is a scenario with a $25 \times$ reduction in exposure and MS No pesticide represents a scenario in which the insecticide was not used. The boxes enclose the 25 th and 75 th percentile, the horizontal center line denotes median values, and box plot whiskers extend to the minimum and maximum values.

alternative management scenarios. We applied a well-established aquatic ecosystem model to quantify the impacts of a hypothetical insecticide on several ecosystem services provided by a generic reservoir lake. Our case study illustrates a modeling framework that can prove useful in evaluating management approaches and resolving tradeoffs in ecosystem services. Although the results are purely dependent on the assumptions and data for this hypothetical case study, they nonetheless show that the best management approach may depend on which services we aim to protect. We have shown that ecosystem services can respond to the presence of an insecticide differently and that careful consideration of service beneficiaries and their values needs to be incorporated into the risk assessment process if ecosystem service delivery is a protection goal.

\subsection{Abundance of game fish}

Hypothetical exposure to the insecticide affected fish species differently. Differences depended on the magnitude of direct effects, i.e. the species sensitivity to the chemical, and indirect effects, i.e. effects mediated through the food web. Both bluegills and their main prey (daphnids) were highly sensitive to the modeled insecticide (lowest toxicity endpoints, SI Table 1). Consequently, management scenarios that resulted in large insecticide runoff to the reservoir resulted in extirpation of both populations. However, at MS 10 and 25 daphnids recovered, but the bluegills did not. Being one of the main preys of largemouth bass, which had the highest biomass at MS 25, resulted in relatively low overall bluegill biomass for the majority of management scenarios. Largemouth bass and walleye experienced similar dynamics (data for walleye not shown because they are the same as bass). Both populations reached very low levels in scenarios with higher insecticide concentrations. However, biomass of both species was highest in a lowinsecticide scenario, MS 25, suggesting that they benefitted from low concentrations of the modeled insecticide in the system. A closer inspection of the trophic matrix (SI Table 2) suggested that a potential cause could be increased detrital biomass which then impacted bass and walleye via the detrital food web. Detritivores, such as chironomids and Tubifex, represent the main food resource for largemouth bass juveniles. However, the prey base for walleye included mostly other fish species such as shad and especially buffalofish, which are relatively insensitive to the modeled insecticide and feeds largely on detritivores. So even though biomass increases of both species were driven by the 
detrital food web, the effect on bass was direct, whereas increased resources for walleye were mediated by intermediary prey species.

On the other end of fish responses was the three-fold increase in catfish biomass in the baseline scenario which could not be explained merely by low sensitivity to the modeled insecticide. The trophic matrix details revealed that walleye substantially rely on catfish and buffalofish and that the insecticide-induced decline in walleye released juvenile catfish from predation; at MS 25 the high walleye biomass induced the biggest decline in catfish out of all management scenarios. Insecticide use also led to an increase in chironomid biomass which forms the base of the catfish diet and thus further increased catfish biomass. A combination of low sensitivity to the insecticide, diminished predation pressure and an increase in prey biomass resulted in overall positive impacts of the modeled insecticide for this species.

These differences in fish biomass dynamics translated into different economic benefits and losses among scenarios, which varied substantially across years. Variability in economic value was expressed as the difference across years attributed to differences in biomass output of AQUATOX. This difference was likely driven by simulated weather that influenced insecticide loading to the reservoir, e.g., increased rainfall leads to increased runoff from treated fields, and by temperature impacts on the simulated community. Year-to-year variability in number of trips or WTP was not accounted for, as these data were not available.

These results illustrate how tradeoffs among ecosystem services may influence management decisions. Because different results were observed for different species of fish, the decision to manage the use of the insecticide for the ecosystem service of angling will depend upon the favored species of fish. If beneficiaries value walleye and bass fishing above fishing for bluegill, any management that reduces insecticide exposure (from MS 10 to MS 100) will be sufficient for improving the ecosystem service of interest. On the other hand, if anglers prefer to fish for bluegill, then only no use of the insecticide in the watershed will be sufficient. Any management of the insecticide would result in economic losses if anglers prefer to fish for catfish.

\subsection{Water clarity}

We simulated the impacts of an insecticide on grazing zooplankton, which resulted in increased phytoplankton biomass and decreased water clarity in the reservoir. Our case study showed that waders and swimmers experienced a monotonic increase in this ecosystem service in response to reduced insecticide use. Water clarity, as measured by Secchi depth, varied substantially across years and simulated scenarios, possibly because phytoplankton biomass is driven by a multitude of factors (Boyce et al., 2010; Carpenter et al., 1998b). Water clarity is affected by ecosystem properties, such as fish community composition and the relative abundance of macrophytes versus algae. In real systems, other drivers also contribute to water clarity, such as suspended sediment (Davies-Colley and Smith, 2001), dissolved organic matter (Solomon et al., 2015) or water chemistry, such as presence of tannins (Stumm and Morgan, 1970). In our hypothetical shallow reservoir, water clarity was mostly driven by changes in food web dynamics, specifically the presence of zooplankton, which is common in shallow lakes (Jeppesen et al., 1999).

The increase in water clarity with reduced insecticide use described above was accompanied by a monotonic increase in value. A significant, linear relationship was reported between Secchi depth and distance traveled to visit lakes in Iowa and Minnesota, as determined by photovisitation (Keeler et al., 2015). The relationship was significant for Iowa lakes alone, where mean Secchi depth was $1.1 \mathrm{~m}$, but not for Minnesota lakes alone, which have a mean Secchi depth of $2.7 \mathrm{~m}$. This may suggest that differences in clarity become less important as clarity improves, a finding that was not possible to consider in our case study. Furthermore, the public benefits more from paying to improve at least one lake to a higher level of clarity than to increase the clarity of all lakes by a smaller amount (Egan et al., 2009). This is, in part, because clarity improvements smaller than $0.5 \mathrm{~m}$ are visually imperceptible (Smeltzer and Heiskary, 1990). In our study, changes in Secchi depth between scenarios with no insecticides and those in which different management strategies were implemented ranged from 0.7 (MS 0 to MS 10) to $1.1 \mathrm{~m}$ (MS 0 to MS No pesticide). This suggests that improvements would be visible to, and presumably valued by the public.

Here, we have demonstrated the implications for management of taking different beneficiary preferences into account. If walleye or largemouth bass are preferred over other fish, then reducing insecticide loading by a factor of 10 would markedly increase service delivery compared to the baseline (no management) scenario. At the same time, catfish would incur a modest reduction in biomass, and there would be a substantial increase in water clarity. In monetary terms, the MS 10 would yield a net benefit of $\sim \$ 670,000$ which is the sum of the mean increased value of largemouth bass, walleye biomass, and bluegill and water clarity. If we were to add the losses associated with reduced catfish, then a net benefit of $\$ 32,000$ would be expected. For comparison, removing insecticide use from the region would yield a benefit of $\$ 1,100,000$; this is the sum of the mean increase in biomass of largemouth bass, walleye, and bluegill and increased water clarity. Subtracting the losses from reduced catfish biomass results in a net value of $\$ 270,000$ over the whole simulation period.

It is worth noting that we did not account for services derived from agriculture in the watershed surrounding this reservoir. Furthermore, we did not account for direct or indirect costs of different management scenarios on agriculture. We assumed that insecticide loading in the watershed could be reduced with different mitigation measures, such as reduced application rates and frequencies or use of buffer strips, or wetlands (Reichenberger et al., 2007); however, these mitigation measures may come at a cost to growers. For example, constructing wetlands may be costly whereas using the appropriate insecticide application nozzle size is less so (Reichenberger et al., 2007). In some cases, mitigation can also generate income for farmers. For example, three-stage buffers from which perennial grasses, willow and poplar are harvested for biomass energy (Jager and Efroymson, 2018; Maringanti et al., 2011). In order to consider additional impacts of possible management options, it may be useful to include a quantitative analysis of the costs or benefits associated with actions that would serve to implement the possible management scenarios.

Furthermore, our hypothetical example was designed to illustrate the worst-case insecticide effects using available models and data expected to be available for an insecticide. The model we used to derive exposure concentrations is conservative in its choice of parameters and assumptions, yielding worst-case exposure concentrations. There are other factors that may impact pesticide loading, such as implementation of agricultural best management practices, use of lower rates (than allowed on the label) and a lower proportion of fields treated within the watershed (i.e., we assumed all of the agricultural acres in the watershed were treated). Analysis of water samples from reservoirs in the Northern Great Plains reveals that for the period of 2003-2005, the maximum detected concentration of the organophosphate chlorpyrifos was $0.02 \mu \mathrm{g} / \mathrm{L}$ (Donald et al., 2007). Observations that empirical concentrations are orders of magnitude lower than modeled estimates (mean simulated concentration was $5 \mu \mathrm{g} / \mathrm{L}$ ), support the assumption that the baseline exposure (MS 0) modeled in this analysis was conservative. This suggests that risk assessments should take into account measured, and not exclusively modeled, exposures. Moreover, other consequences of agricultural practices were also omitted from this study. Nutrient run-off may cause substantial disruption to aquatic ecosystems, including algal blooms, hypoxic events or shifts in the whole food web (Carpenter et al., 1998a; Scheffer et al., 1993). Increased input of suspended inorganic solids has been demonstrated to adversely affect biomass and diversity of both plants and consumers in streams and experimental systems (Matthaei et al., 2010; Townsend et al., 2008). However, our aim was not to perform an actual risk assessment, which would need to take into account various other sources of stress, 
but instead to provide an example of how provision of ecosystem services to different beneficiaries can be simulated under different insecticide management scenarios to facilitate decision-making in ecological risk assessment and management (Evans et al., 2013; Forbes et al., 2017). To clearly demonstrate this, we used a wide range of exposures that ensured a larger disruption to the ecosystem and possible ecosystem service trade-offs. Finally, it is also important to note that pesticides with other modes of action would likely result in different outcomes. Quantifying impacts on ecosystem services from exposure to herbicides, fungicides, or other insecticides, was beyond the aims of this study. However, if toxicity data exist, the methodology reported here could readily be applied to other classes of chemicals.

Our study clearly showed the importance of considering nonlinear ecosystem feedbacks when attempting to assess risk from chemicals and other stressors (De Laender and Janssen, 2013). The presence of some level of insecticide changed the modeled food-web dynamics in non-linear ways, resulting in increased catfish biomass in all scenarios, and walleye and largemouth bass in low insecticide scenarios (MS 25 ). It is highly unlikely that such responses would have been detected without the use of quantitative models that integrate relevant ecological information. Our study highlights one of the main advantages of using ecological models for risk assessment, namely the ability to generalize to meaningful levels of organization that matter to society, rather than individual-level toxicological sensitivity of a handful of species (Forbes and Galic, 2016; Forbes et al., 2017). The models also facilitate quantitative comparisons among alternative scenarios while explicitly accounting for different groups of beneficiaries and potential trade-offs among them. This approach has the potential to enhance the transparency and consistency of risk assessments by enlisting and representing different stakeholder communities, and may thereby improve environmental management decisions.

\section{Acknowledgements}

The present study was conducted as part of the Organisms to Ecosystems Working Group at the National Institute for Mathematical and Biological Synthesis, sponsored by the National Science Foundation through award DBI-1300426, with additional support from The University of Tennessee, Knoxville. HJ is employed by UT-Battelle, LLC which is managed under Contract No. DE-AC05-000R22725 with the U.S. Department of Energy. The publisher, by accepting the article for publication, acknowledges that the US Government retains a non-exclusive, paid-up, irrevocable, world-wide license to publish or reproduce the published form of this manuscript, or allow others to do so, for US Government purposes. The Department of Energy will provide public access to these results of federally sponsored research in accordance with the DOE Public Access Plan (http://energy.gov/downloads/doe-publicaccess-plan). We also thank one anonymous reviewer for their helpful comments and suggestions on an earlier version of the manuscript.

\section{Appendix A. Supplementary data}

Supplementary data to this article can be found online at https://doi. org/10.1016/j.scitotenv.2019.05.187.

\section{References}

Bennett, E.M., Peterson, G.D., Gordon, L.J., 2009. Understanding relationships among multiple ecosystem services. Ecol. Lett. 12, 1394-1404.

Boyce, D.G., Lewis, M.R., Worm, B., 2010. Global phytoplankton decline over the past century. Nature 466, 591.

Boyd, J., Banzhaf, S., 2007. What are ecosystem services? The need for standardized environmental accounting units. Ecol. Econ. 63, 616-626.

Bruins, R.J.F., Canfield, T.J., Duke, C., Kapustka, L., Nahlik, A.M., Schäfer, R.B., 2017. Using ecological production functions to link ecological processes to ecosystem services. Integr. Environ. Assess. Manag. 13, 52-61.

Carpenter, S.R., Kitchell, J.F., Hodgson, J.R., 1985. Cascading trophic interactions and lake productivity. BioScience 35, 634-639.
Carpenter, S.R., Caraco, N.F., Correll, D.L., Howarth, R.W., Sharpley, A.N., Smith, V.H., 1998a. Nonpoint pollution of surface waters with phosphorus and nitrogen. Ecol. Appl. 8, 559-568.

Carpenter, S.R., Cole, J.J., Kitchell, J.F., Pace, M.L., 1998b. Impact of dissolved organic carbon, phosphorus, and grazing on phytoplankton biomass and production in experimental lakes. Limnol. Oceanogr. 43, 73-80.

Carpenter, S.R., Cole, J.J., Kitchell, J.F., Pace, M.L., 2010. Trophic Cascades in Lakes: Lessons and Prospects. Trophic Cascades: Predators, Prey and the Changing Dynamics of Nature. pp. 55-69.

Charbonneau, J.J., Hay, M.J., 1978. Determinants and economic values of hunting and fishing. Transactions of the Forty-third North American Wildlife and Natural Resources Conference, March 18-22 Phoenix, Arizona. Wildlife Management Institute. 391-403.

Clough, J.S., Blancher II, E.C., Park, R.A., Milroy, S.P., Graham, W.M., Rakocinski, C.F., et al., 2017. Establishing nearshore marine injuries for the Deepwater Horizon natural resource damage assessment using AQUATOX. Ecol. Model. 359, 258-268.

Davies-Colley, R., Smith, D., 2001. Turbidity, suspended sediment, and water clarity: a review. JAWRA Journal of the American Water Resources Association 37, 1085-1101.

De Laender, F., Janssen, C.R., 2013. Brief communication: the ecosystem perspective in ecotoxicology as a way forward for the ecological risk assessment of chemicals. Integr. Environ. Assess. Manag. 9, e34-e38.

Dodds, W.K., Bouska, W.W., Eitzmann, J.L., Pilger, T.J., Pitts, K.L., Riley, A.J., et al., 2008. Eutrophication of US Freshwaters: Analysis of Potential Economic Damages. ACS Publications.

Donald, D.B., Cessna, A.J., Sverko, E., Glozier, N.E., 2007. Pesticides in surface drinkingwater supplies of the Northern Great Plains. Environ. Health Perspect. 115, 1183-1191.

Efroymson, R.A., Carlsen, T.M., Jager, H.I., Kostova, T., Carr, E.A., Hargrove, W.W., et al., 2004. Toward an ecological framework for assessing risk to vertebrate populations from brine and petroleum spills at exploration and production sites. Landscape Ecology and Wildlife Habitat Evaluation: Critical Information for Ecological Risk Assessment, LandUse Management Activities, and Biodiversity Enhancement. ASTM International.

Efroymson, R.A., Jager, H.I., Hargrove, W.W., 2010. Valuing wildlands. In: Kapustka, L., Landis, W. (Eds.), Environmental Risk Assessment and Management from a Landscape Perspective. vols. 156-185. John Wiley \& Sons, pp. 156-185.

Egan, K.J., Herriges, J.A., Kling, C.L., Downing, J.A., 2009. Valuing water quality as a function of water quality measures. Am. J. Agric. Econ. 91, 106-123.

Evans, M.R., Bithell, M., Cornell, S.J., Dall, S.R.X., Díaz, S., Emmott, S., et al., 2013. Predictive systems ecology. Proc. R. Soc. B Biol. Sci. 280.

Fisher, B., Turner, R.K., Morling, P., 2009. Defining and classifying ecosystem services for decision making. Ecol. Econ. 68, 643-653.

Forbes, V.E., Galic, N., 2016. Next-generation ecological risk assessment: predicting risk from molecular initiation to ecosystem service delivery. Environ. Int. 91, 215-219.

Forbes, V.E., Salice, C.J., Birnir, B., Bruins, R.J.F., Calow, P., Ducrot, V., et al., 2017. A framework for predicting impacts on ecosystem services from (sub)organismal responses to chemicals. Environ. Toxicol. Chem. 36, 845-859.

Galic, N., Schmolke, A., Forbes, V., Baveco, H., van den Brink, P.J., 2012. The role of ecological models in linking ecological risk assessment to ecosystem services in agroecosystems. Sci. Total Environ. 415, 93-100.

Ge, J., Kling, C., Herriges, J., 2013. How much is clean water worth? Valuing water quality improvement using a meta analysis. Economics Working Papers (2002-2016), p. 38.

Hommen, U., Baveco, J.M., Galic, N., Van Den Brink, P.J., 2010. Potential application of ecological models in the european environmental risk assessment of chemicals I: review of protection goals in EU directives and regulations. Integr. Environ. Assess. Manag. 6, 325-337.

Jager, H.I., Efroymson, R.A., 2018. Can upstream biofuel production increase the flow of downstream ecosystem goods and services? Biomass and Bioenergy 114, 125-131.

Jeppesen, E., Jensen, J.P., Søndergaard, M., Lauridsen, T., 1999. Trophic Dynamics in Turbid and Clearwater Lakes with Special Emphasis on the Role of Zooplankton for Water Clarity. Shallow lakes' 98. Springer, pp. 217-231.

Johnston, E.L., Mayer-Pinto, M., Crowe, T.P., 2015. REVIEW: chemical contaminant effects on marine ecosystem functioning. J. Appl. Ecol. 52, 140-149.

Keeler, B.L., Wood, S.A., Polasky, S., Kling, C., Filstrup, C.T., Downing, J.A., 2015. Recreational demand for clean water: evidence from geotagged photographs by visitors to lakes. Front. Ecol. Environ. 13, 76-81.

Kosten, S., Lacerot, G., Jeppesen, E., Marques, D.D., van Nes, E.H., Mazzeo, N., et al., 2009. Effects of submerged vegetation on water clarity across climates. Ecosystems 12, 1117-1129.

Landers, D.H., Nahlik, A.M., 2013. Final Ecosystem Goods and Services Classification System (FEGS-CS). Anonymous EPA United States Environmental Protection Agency Report Number EPA/600/R-13/ORD-004914.

Luck, G.W., Daily, G.C., Ehrlich, P.R., 2003. Population diversity and ecosystem services. Trends Ecol. Evol. 18, 331-336.

Maringanti, C., Chaubey, I., Arabi, M., Engel, B., 2011. Application of a multi-objective optimization method to provide least cost alternatives for NPS pollution control. Environ. Manag. 48, 448-461.

Matthaei, C.D., Piggott, J.J., Townsend, C.R., 2010. Multiple stressors in agricultural streams: interactions among sediment addition, nutrient enrichment and water abstraction. J. Appl. Ecol. 47, 639-649.

Melstrom, R.T., Lupi, F., Esselman, P.C., Stevenson, R.J., 2015. Valuing recreational fishing quality at rivers and streams. Water Resour. Res. 51, 140-150.

Nienstedt, K.M., Brock, T.C.M., van Wensem, J., Montforts, M., Hart, A., Aagaard, A., et al., 2012. Development of a framework based on an ecosystem services approach for deriving specific protection goals for environmental risk assessment of pesticides. Sci. Total Environ. 415, 31-38.

Park, R., Clough, J., 2014. AQUATOX (RELEASE 3.1 plus): modeling environmental fate and ecological effects in aquatic ecosystems. In: Agency, E.P. (Ed.), Volume 2: Technical Documentation. 
Park, R.A., Clough, J.S., Wellman, M.C., 2008. AQUATOX: modeling environmental fate and ecological effects in aquatic ecosystems. Ecol. Model. 213, 1-15.

Peeters, E., Franken, R.J.M., Jeppesen, E., Moss, B., Becares, E., Hansson, L.A., et al., 2009. Assessing ecological quality of shallow lakes: does knowledge of transparency suffice? Basic and Applied Ecology 10, 89-96.

Postel, S., Carpenter, S., 1997. Freshwater Ecosystem Services. Nature's Services: Societal Dependence on Natural Ecosystems. vol. 195.

Reichenberger, S., Bach, M., Skitschak, A., Frede, H.-G., 2007. Mitigation strategies to reduce pesticide inputs into ground- and surface water and their effectiveness; a review. Sci. Total Environ. 384, 1-35.

Richardson, L., Loomis, J., Kroeger, T., Casey, F., 2015. The role of benefit transfer in ecosystem service valuation. Ecol. Econ. 115, 51-58.

Scheffer, M., Hosper, S., Meijer, M., Moss, B., Jeppesen, E., 1993. Alternative equilibria in shallow lakes. Trends Ecol. Evol. 8, 275-279.

Schnoor, J.L., 1981. Fate and transport of dieldrin in Coralville reservoir: residues in fish and water following a pesticide ban. Science $211,840-842$.

Schuetz, J.F., Boyle, K.J., Bouchard, R., 2001. The effects of water clarity on economic values and economic impacts of recreational uses of Maine's great ponds. Maine Agricultural \& Forest Experiment Station 25.

Smeltzer, E., Heiskary, S.A., 1990. Analysis and applications of lake user survey data. Lake and Reservoir Management 6, 109-118.
Solomon, C.T., Jones, S.E., Weidel, B.C., Buffam, I., Fork, M.L., Karlsson, J., et al., 2015. Ecosystem consequences of changing inputs of terrestrial dissolved organic matter to lakes: current knowledge and future challenges. Ecosystems 18, 376-389.

Stumm, W., Morgan, J.J., 1970. Aquatic Chemistry; an Introduction Emphasizing Chemical Equilibria in Natural Waters.

Suter, G.W., Barnthouse, L.W., Efroymson, R.A., Jager, H., 1999. Ecological risk assessment in a large river-reservoir: 2. Fish community. Environ. Toxicol. Chem. 18, 589-598.

Tilman, D., Clark, M., Williams, D.R., Kimmel, K., Polasky, S., Packer, C., 2017. Future threats to biodiversity and pathways to their prevention. Nature 546, 73-81.

Townsend, C.R., Uhlmann, S.S., Matthaei, C.D., 2008. Individual and combined responses of stream ecosystems to multiple stressors. J. Appl. Ecol. 45, 1810-1819.

U.S. Army Corps of Engineers, 2014. Coralville Lake Fact Sheet.

U.S. Environmental Protection Agency, 1993. Wildlife Exposure Factors Handbook. Office of Research and Development, Washington, DC.

Viscusi, W.K., Huber, J., Bell, J., 2008. The economic value of water quality. Environ. Resour. Econ. 41, 169-187.

Young, D.F., 2016. The Variable Volume Water Model: Revision A. U.S. Environmental Protection Agency, Washington, D.C.

Young, D.F., Fry, M.M., 2016. PRZM: A Model for Predicting Pesticides in Runoff, Erosion, and Leachate: Revision A. U.S. Environmental Protection Agency, Washington D.C. 